\title{
Paquidermodactilia transgressiva: relato de um caso ${ }^{*}$
}

\author{
Transgrediens pachydermodactyly: report of a case
}

\author{
Lia Rachel Gomes do Vale ${ }^{1}$ \\ Nilceo Michalany ${ }^{3}$ \\ Adriana Maria Porro 5
}

\author{
Flávia Regina Coeli ${ }^{2}$ \\ Karime Marques Hassun ${ }^{4}$
}

\begin{abstract}
Resumo: A paquidermodactilia é forma rara de fibromatose digital envolvendo as porções proximais dos dedos, que afeta homens jovens. Apresenta-se caso de paciente de 25 anos com quadro de nódulos assintomáticos nas mãos há dois anos, e há três meses com lesões semelhantes nos pés e no joelho direito. $\mathrm{O}$ exame histopatológico revelou espessamento da derme com proliferação de fibroblastos e de fibras colágenas e aumento de mucina. O caso descrito corresponde à paquidermodactilia do tipo transgressiva.

Palavras-chave: Corticosteróides; Dermatoses da mão; Fibroma

Abstract: Pachydermodactyly is a rare form of digital fibromatosis involving the proximal portions of the fingers that usually affects young males. We present a 25 -year-old male patient with a twoyear history of asymptomatic nodules in the fingers. Three months before the visit, he had observed similar lesions on the feet and right knee. Histopathological analysis showed thickened dermis with proliferation of fibroblasts and collagenous fibers, with deposition of mucinous material. This represents a rare case of pachydermodactyly of transgrediens form.

Keywords: Adrenal cortex hormones; Fibroma; Hand dermatosis
\end{abstract}

\section{INTRODUÇÃO}

A paquidermodactilia é forma rara e benigna de fibromatose digital que acomete porções proximais dos dedos e afeta geralmente adultos jovens do sexo masculino. ${ }^{1}$ Foi descrita por Verbov em $1975^{2}$ e caracteriza-se clinicamente por aumento assintomático de partes moles em torno das falanges proximais e articulações interfalangianas. ${ }^{3}$

O caso aqui relatado é de um paciente com quadro de paquidermodactilia em mãos e pés, além de paquidermia no joelho direito.

\section{RELATO DO CASO}

Paciente do sexo masculino de 25 anos, com antecedente de retardo mental desde o nascimento, referindo nódulos assintomáticos nas mãos que surgiram há cerca de dois anos e cujo tamanho aumentou progressivamente. Cerca de três meses antes da consulta notara o aparecimento de lesões semelhantes nos pés e no joelho direito. Negou traumatismos repetitivos nas mãos e casos semelhantes na família.

O exame físico geral apresentou-se sem anormalidades.

\footnotetext{
Recebido em 20.09.2006.

Aprovado pelo Conselho Consultivo e aceito para publicação em 28.09.07.

* Trabalho realizado nos departamentos de Dermatologia e Patologia da Universidade Federal de São Paulo (Unifesp) - Escola Paulista de Medicina - São Paulo (SP), Brasil.

Conflito de interesse: Nenhum / Conflict of interest: None

Suporte financeiro: Nenhum / Financial funding: None

Médica residente em Dermatologia da Universidade Federal de São Paulo (Unifesp) - São Paulo (SP), Brasil

Médica especializanda em dermatologia pediátrica e ex-residente de dermatologia da Universidade Federal de São Paulo (Unifesp) - São Paulo (SP), Brasil.

Médico do Departamento de Patologia da Universidade Federal de São Paulo (Unifesp) - São Paulo (SP), Brasil.

Médica do Departamento de Dermatologia. Mestre em dermatologia. Universidade Federal de São Paulo (Unifesp) - São Paulo (SP), Brasil.

Professora adjunta do Departamento de Dermatologia. Doutora em dermatologia. Universidade Federal de São Paulo (Unifesp) - São Paulo (SP), Brasil. 
Ao exame dermatológico observaram-se nódulos de consistência fibroelástica localizados na face lateral da segunda articulação metacarpofalangiana direita (Figura 1), face medial da primeira articulação metacarpofalangiana esquerda, dorso dos primeiros pododáctilos bilateralmente (Figura 2) e nos calcâneos. A pele em torno das falanges proximais dos quirodáctilos e na face extensora do joelho direito encontrava-se espessada.

Exames complementares apresentaram hemograma normal; ácido úrico normal $(4,4 \mathrm{mg} / \mathrm{dl})$. Radiografia das mãos: morfologia óssea preservada; interlinhas articulares mantidas; pequeno aumento de partes moles no nível da terceira e da quarta articulação interfalangiana à direita e da segunda articulação metacarpofalangiana bilateral. Ausência de espessamento periosteal. Radiografia dos pés: textura e morfologia ósseas normais, sem evidências de lesões ósseas focais.

A ultrassonografia de partes moles das mãos mostrava formações sólidas com sinais de vascularização em seu interior, heterogêneas e de limites parcialmente definidos no plano subcutâneo, medindo $2,5 \times 0,9 \times$ $1,8 \mathrm{~cm}$ na base do segundo quirodáctilo direito e $2,6 \mathrm{x}$ $1,7 \times 0,9 \mathrm{~cm}$ na base do primeiro quirodáctilo esquerdo.

O exame histopatológico da pele do segundo quirodáctilo direito revelou acentuado espessamento da derme com hiperqueratose. Na derme profunda observou-se proliferação de fibroblastos e de fibras colágenas (Figuras 3 e 4). A coloração com ferro coloidal revelou aumento de mucina na derme (Figura 5).

O tratamento instituído foi infiltração intralesional de acetonido de triamcinolona na concentração

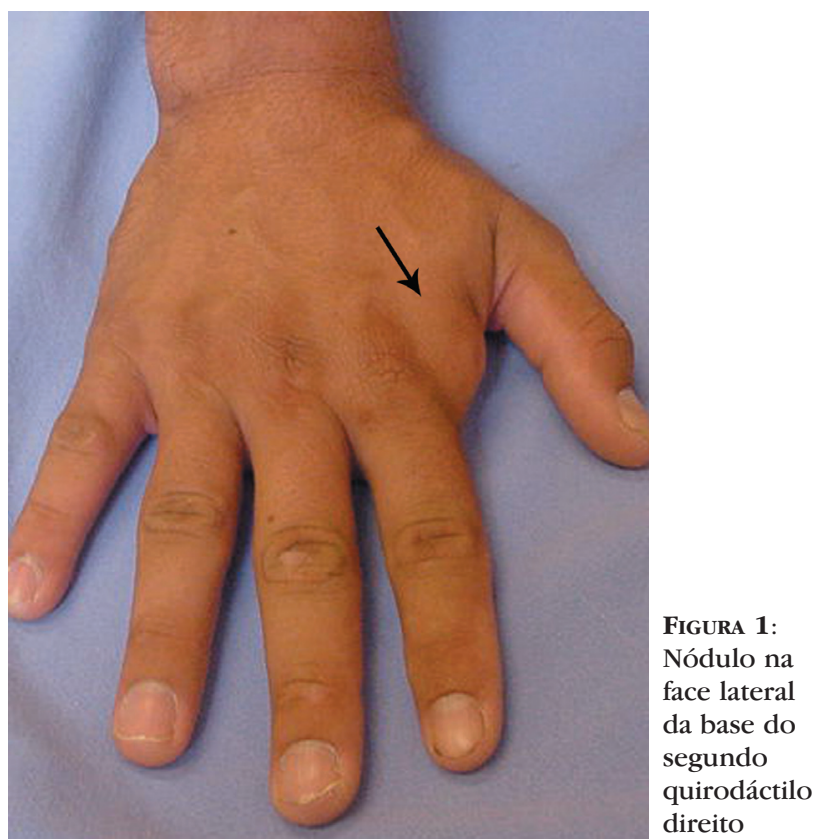

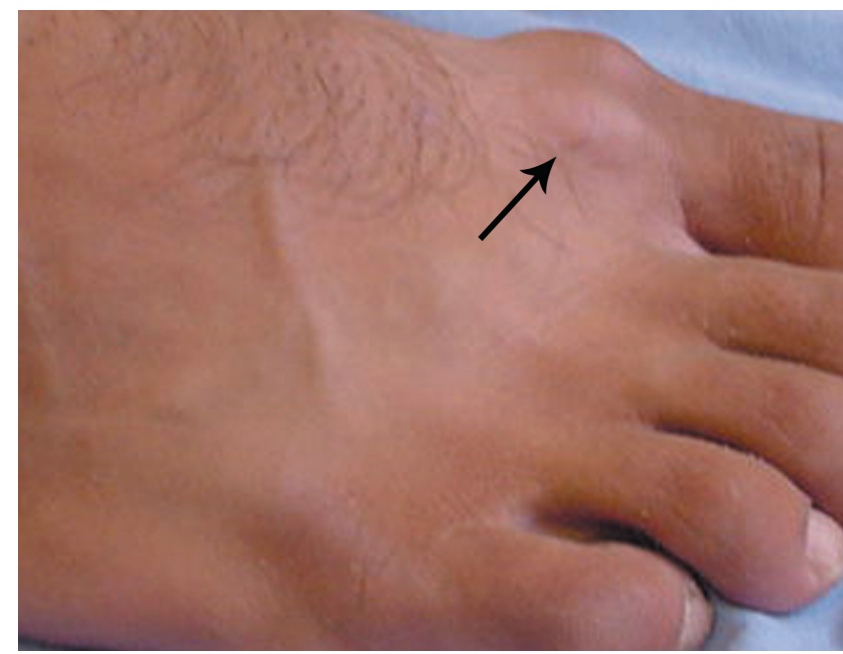

Figura 2: Nódulo na região dorsal da base do primeiro pododáctilo direito

de $20 \mathrm{mg} / \mathrm{ml}$, observando-se regressão das lesões após três aplicações.

\section{DISCUSSÃO}

A paquidermodactilia é condição benigna e indolor que produz edema e espessamento da pele em torno das regiões dorsal e lateral das falanges e articulações interfalangianas proximais dos dedos. ${ }^{4}$

Várias formas de paquidermodactilia têm sido descritas dependendo da topografia, etiologia e associações patológicas: 1) clássica, na qual há o acometimento de muitos dedos de ambas as mãos, atribuído a trauma local; 2) monopaquidermodactilia ou paquidermodactilia localizada, com acometimento de um só dedo; 3) transgressiva, na qual o espessamento cutâneo atinge outras áreas além dos dedos das mãos, como as regiões metacarpofalangianas; 4) familiar; e

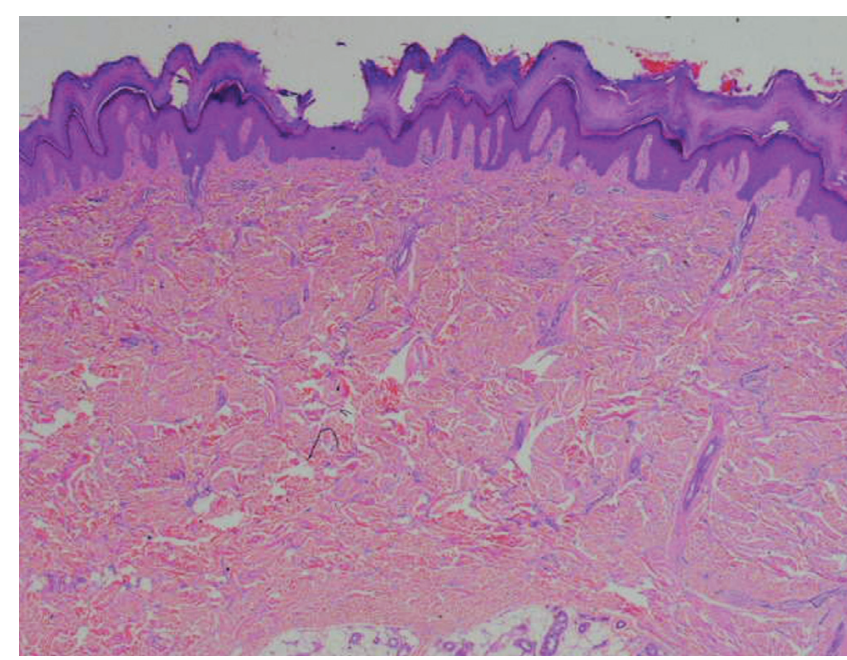

Figura 3: Acentuado espessamento da derme com hiperqueratose $\mathrm{HE}(25 \mathrm{x})$ 


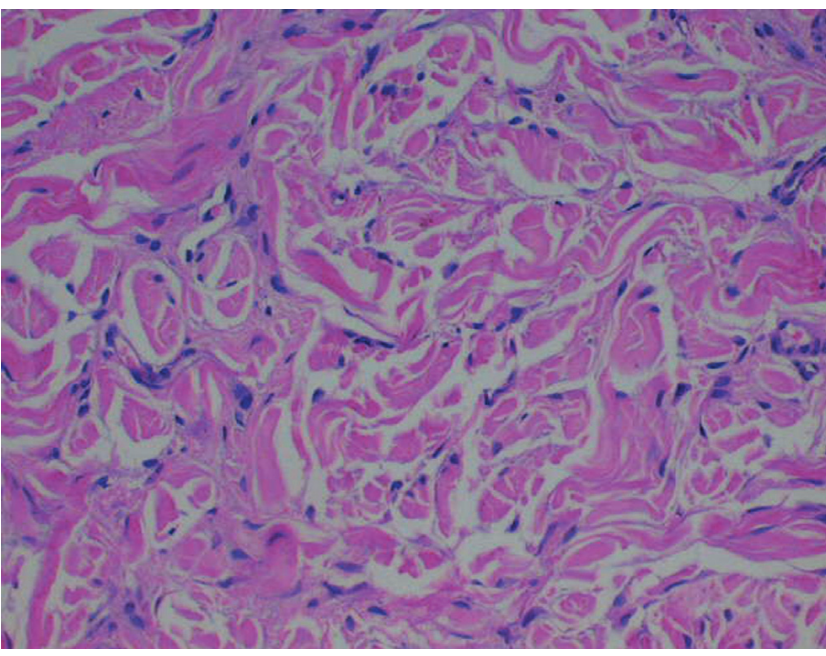

Figura 4: Proliferação fibroblástica desordenada com espessamento das fibras colágenas e mucina de permeio HE (100x)

5) paquidermodactilia associada a esclerose tuberosa. ${ }^{4}$ $\mathrm{O}$ caso aqui descrito corresponde à paquidermodactilia transgressiva, com acometimento dos dedos das mãos, articulações metacarpo e metatarsofalangianas, além da região plantar e do joelho direito. A associação de paquidermodactilia com aspecto paquidérmico do joelho nunca havia sido descrita na literatura. Apenas um relato de associação com paquidermia plantar foi encontrado. ${ }^{5}$

O tipo transgressivo constitui forma excepcional de paquidermodactilia, com poucos casos descritos na literatura. É caracterizada pela extensão do espessamento cutâneo dos quirodáctilos para as regiões metacarpofalangianas. No paciente em questão esse fato é observado através do acometimento da primeira articulação metacarpofalangiana esquerda e segunda articulação metacarpofalangiana direita. Além disso, foi observado aspecto paquidérmico nas regiões do calcâneo, articulações metatarsofalangianas e do joelho direito. ${ }^{6}$

A etiologia da paquidermodactilia permanece desconhecida. Trata-se de doença geralmente adquiri$\mathrm{da}$, ainda que algumas publicações documentem casos familiares. ${ }^{4,7}$ Tem sido sugerido que traumas mecânicos repetidos, como o hábito de friccionar os dedos, levariam ao desenvolvimento desse espessamento cutâneo. ${ }^{1}$ No caso apresentado não há relato de estímulos repetidos nos dedos, apesar de tratar-se de paciente com déficit intelectual.

O exame histopatológico habitualmente revela hiperqueratose e espessamento importante da derme devido à deposição de fibras colágenas, com vários graus de celularidade. Estes achados são comparáveis aos observados no paciente aqui descrito. Colágeno dos tipos III e V estão aumentados, e a microscopia

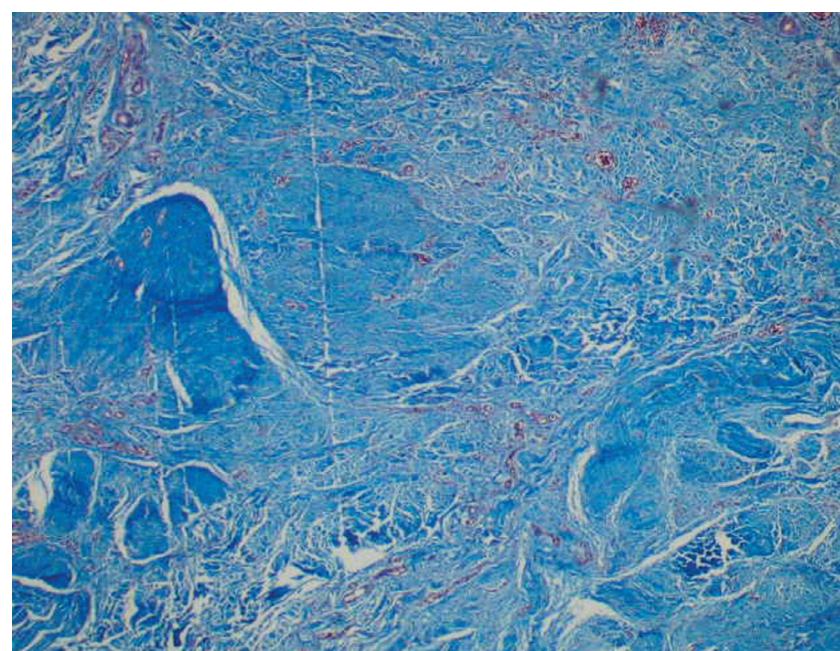

Figura 5: Ferro coloidal - aumento de mucina na derme (40x)

eletrônica mostra aumento do número de fibras colágenas de fino diâmetro. Pode haver depósito de mucina entre as fibras colágenas. ${ }^{8}$

O diagnóstico diferencial de paquidermodactilia deve ser feito principalmente com coxim falangiano, cuja distinção ocorre através da localização do aumento de volume em torno das articulações interfalangianas proximais: dorsal no coxim falangiano e predominantemente lateral na paquidermodactilia. Além disso, coxins falangianos podem ser encontrados em ambos os sexos e ampla faixa etária.1 Outros possíveis diagnósticos diferenciais são o granuloma de corpo estranho, fibroma e artropatias. ' Não deve também haver confusão com paquidermoperiostose, na qual se evidenciam herança autossômica dominante, baqueteamento digital, além de alterações ósseas e do couro cabeludo. ${ }^{10,11}$

As condições coexistentes relacionadas com paquidermodactilia incluem a esclerose tuberosa, a atrofia maculosa varioliforme cútis, a contratura de Dupuytren, a síndrome do túnel do carpo e a síndrome de Ehlers-Danlos. ${ }^{8}$

$\mathrm{O}$ tratamento da paquidermodactilia consiste na suspensão dos estímulos mecânicos repetitivos (nos casos associados), no uso de corticóide intralesional ou na excisão completa da lesão. ${ }^{11}$ No caso aqui relatado foi realizado tratamento com infiltração de corticóide intralesional, observando-se significativa melhora das lesões.

A paquidermodactilia é doença rara, pouco conhecida e provavelmente subnotificada. Relatou-se caso de paquidermodactilia transgressiva associada a acometimento plantar e de joelho, este último inédito na literatura. 


\section{REFERÊNCIAS}

1. Kim TH, Cho YH, Park HB. Two cases of pachydermodactyly. J Dermatol. 1996;23:419-24.

2. Verbov J. Pachydermodactyly: a variant of the true knuckle pads. Arch Dermatol. 1975;111:524.

3. Kopera D, Soyer HP, Kerl H. An update on pachydermodactyly and a report of three additional cases. Br J Dermatol. 1995;133:433-7.

4. Bardazzi F, Neri I, Raone B, Patrizi A. Pachydermodactyly: seven new cases. Ann Dermatol Venereol. 1998;125:247-50.

5. Marcilly MC, Balme B, Luaute JP, Skowron F, Berard F, Perrot H. Pachydermatodactyly associated with plantar pachydermy. Ann Dermatol Venereol. 2003;130 (Pt 1):777-80.

6. Sola A, Vazquez-Doval J, Sola J, Quintanilla E. Pachydermodactyly transgrediens. Int J Dermatol. 1992;31:796-7.

7. Russo F, Rodriguez-Pichardo A, Camacho F. Familial pachydermodactyly. Acta Derm Venereol. 1994;74:386-7.

8. Burrows NP, Lovell CR. Disorders of Connective Tissue. In: Burns T, Breathnach S, Cox N, Griffiths C. Rook 's textbook of dermatology. 7th ed. Massachusetts: Blackwell Science; 2004. p 46-50.
9. Ye S, Chen S, Dong Y, Lin F, Guo Q, Bao C. Pachydermodactyly - Six new cases from China. J Clin Rheumatol. 2005;11:72-5.

10. Rai A, Zaphiropoulos GC. An Unusual case of peri-articular soft tissue finger swelling in an adolescent male: pachydermodactyly or pachydermoperiostosis? $\mathrm{Br} \mathrm{J}$ Rheumatol. 1994;33:677-9.

11. Chamberlain AJ, Venning VA, Wojnarowska $F$. Pachydermodactyly: a forme fruste of knuckle pads? Australas J Dermatol. 2003;44:140-3.

ENDEREÇO PARA CORRESPONDÊNCIA / MAILING ADDRESS:

Lia Rachel Gomes do Vale

Rua Estado de Israel, 701 Apto. 23 Vila Clementino

04022002 - São Paulo - SP

Tel./fax: (011) 5084-1286 9628-1430 5576-4135

Como citar este artigo/How to cite this article: Vale LRG, Coeli FR, Michalany N, Hassun KM, Porro AM. Paquidermodactilia transgressiva: relato de um caso. An Bras Dermatol. 2009;84(2):190-3. 